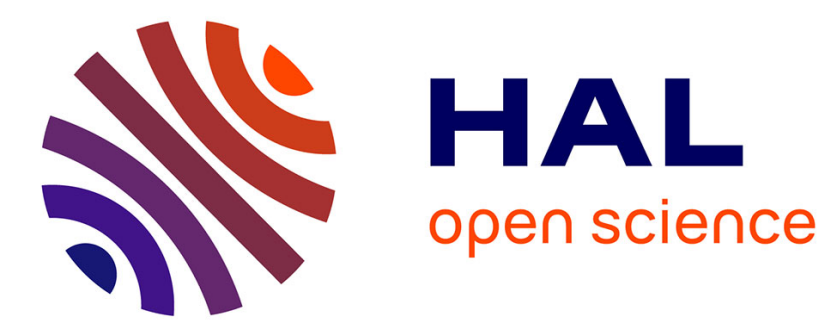

\title{
Domain Walls Motions in Barium Titanate Ceramics
}

\author{
B. Cheng, M. Gabbay, Mario Maglione, Yves Jorand, Gilbert Fantozzi
}

\section{To cite this version:}

B. Cheng, M. Gabbay, Mario Maglione, Yves Jorand, Gilbert Fantozzi. Domain Walls Motions in Barium Titanate Ceramics. Journal de Physique IV Proceedings, 1996, 06 (C8), pp.C8-647-C8-650. 10.1051/jp4:19968139 . jpa-00254571

\section{HAL Id: jpa-00254571 https://hal.science/jpa-00254571}

Submitted on 1 Jan 1996

HAL is a multi-disciplinary open access archive for the deposit and dissemination of scientific research documents, whether they are published or not. The documents may come from teaching and research institutions in France or abroad, or from public or private research centers.
L'archive ouverte pluridisciplinaire HAL, est destinée au dépôt et à la diffusion de documents scientifiques de niveau recherche, publiés ou non, émanant des établissements d'enseignement et de recherche français ou étrangers, des laboratoires publics ou privés. 


\title{
Domain Walls Motions in Barium Titanate Ceramics
}

\author{
B.L. Cheng*, M. Gabbay, M. Maglione**, Y. Jorand and G. Fantozzi \\ GEMPPM, UMR 5510 du CNRS, INSA de Lyon, 69621 Villeurbanne cedex, France \\ * Department of Physics, South China University of Technology, Guangzhou 510641, China \\ ** Laboratoire de Physique, URA 785 du CNRS, Université de Bourgogne, 21004 Dijon cedex, France
}

\begin{abstract}
The shear modulus and mechanical loss at low frequencies $(0.01,0.3,1 \mathrm{~Hz})$ are measured by an inverted pendulum for $\mathrm{BaTiO}_{3}$ ceramic with large grain sizes. The permittivity and dielectric losses are also investigated for the same material at higher frequencies between 1 and $100 \mathrm{kHz}$ as function of temperature. Those results show several relaxation peaks in the ferroelectric phases. The activation energy of each peak is obtained to be $0.29,0.45$, $0.68,0.92 \mathrm{eV}$. The influences of strain amplitude and thermal treatments are studied specially for the mechanical relaxation peak located in the tetragonal phase. All the relaxation peaks could be associated to the interaction of oxygen vacancies in the domain with different configurations of domain walls by piezoelectric effect. The experimental results show there is one peak occurring in all the three ferroelectric phases, which could mean that the ferroelectric domain structures have certain memory effect.
\end{abstract}

\section{INTRODUCTION}

Ferroelectric $\mathrm{BaTiO}_{3}$ ceramics are widely used as multilayer capacitors, non-linear positive-temperaturecoefficient resistors, and piezoelectric transducers [1]. For all the applications the motion of domain wall play a decisive role. The previous studies by flexural vibration at kilohertz $[2,3]$ on undoped coarse grained $\mathrm{BaTiO}_{3}$ ceramics show three phase transition peak $(\mathrm{T})$ and other mechanical loss peaks $\left(\mathrm{R}^{\mathrm{m}}\right)$ in the ferroelectric crystalline phase. Such relaxation peaks do not appear in the ceramics with small grain sizes $(1-2 \mu \mathrm{m})$ [2] and have not been observed by other researchers [4,5]. Those peaks $\left(\mathrm{R}^{\mathrm{m}}\right)$ have been associated to the domain walls motion. However, there are still different models for the movements of domain walls in the ferroelectric materials [6-8]. In the present report, by measurements of mechanical losses at low frequency and dielectric losses at high frequency, we try to verify whether the peaks $\mathrm{R}^{\mathrm{m}}$ are really the relaxation processes, by studying the influence of thermal treatment we try to clarify the mechanism of the loss peak.

\section{EXPERIMENTAL PROCEDURE}

The preparation of $\mathrm{BaTiO}_{3}$ ceramics is described in [2]. The shear modulus and mechanical losses at low frequencies $(0.01,0.3,1 \mathrm{~Hz})$ are measured by an inverted pendulum from $-150^{\circ} \mathrm{C}$ to $150^{\circ} \mathrm{C}$. The permittivity and dielectric loss are measured in the same temperature range at frequencies between 1-100 $\mathrm{kHz}$ by using an automatic impedance meter HP4192A.

\section{RESULTS}

Fig. 1 shows the curves of shear modulus $G(T)$ and mechanical losses $Q^{-1}(T)$ of $\mathrm{BaTiO}_{3}$ ceramic with large grain sizes (about $40 \mu \mathrm{m}$ ). There are three anomalies on the curves of shear modulus: $\mathrm{A}_{1}\left(125^{\circ} \mathrm{C}\right.$ ), $\mathrm{A}_{2}\left(20^{\circ} \mathrm{C}\right)$, and $\mathrm{A}_{3}\left(-70^{\circ} \mathrm{C}\right)$ for the three frequencies of $1,0.1$, and $0.01 \mathrm{~Hz}$ during heating $0.25^{\circ} \mathrm{C} / \mathrm{min}$. The temperatures of anomalies do not change with frequencies, and can be attributed to the following phase transitions: tetragonal to cubic phase, orthorhombic to tetragonal phase, and rhombohedral to 
orthorhombic phase. The $\mathrm{Q}^{-1}$ curves exhibit not only three peaks of $\mathrm{P}_{1}, \mathrm{P}_{2}$, and $\mathrm{P}_{3}$ corresponding to the anomalies of modulus, but also other peaks located in the three ferroelectric phases. With increasing of frequency the peak temperature increased, which shows a relaxation behavior. In order to describe the results clearly, those loss peaks are noted, such as $R_{R}^{\mathfrak{m}}$, for the peak located in the rhombohedral phase (R-phase) measured by mechanical vibrations, and $\mathrm{R}_{\mathrm{O}}^{\mathrm{e}}$, for the peak located in the orthorhombic phase (O-phase) measured by electric excitation.

Fig. 2 shows the curves of permittivity $\varepsilon(T)$, and dielectric loss $\tan \delta(T)$ as a function of temperature $T$ for the frequencies of $1,3,10,100 \mathrm{kHz}$ for the same sample as in the Fig. 1 during heating. The $\varepsilon(\mathrm{T})$ curves show three peaks at $127,13^{\circ} \mathrm{C}$, and $-72^{\circ} \mathrm{C}$ corresponding to the three phase transitions. In the tan $\delta$ curves there are also other peaks located respectively at the R-phase, O-phase, and T-phase. The peak temperatures $T_{P}$ of each peak is shifted to higher temperatures as increasing vibration frequencies.

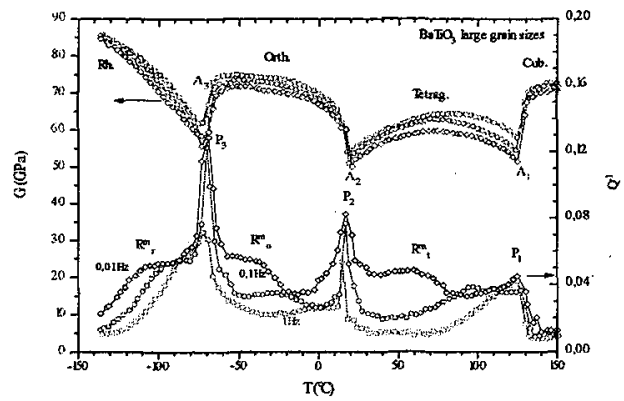

Fig. 1 Variation of mechanical loss $Q^{-1}(T)$ and shear modulus $\mathrm{G}(\mathrm{T})$ in $\mathrm{BaTiO}_{3}$ ceramic with large grain sizes

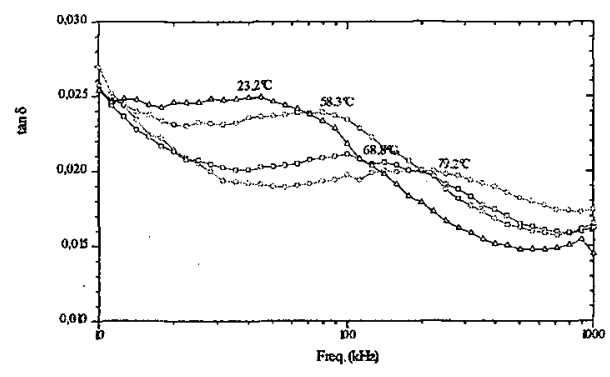

Fig. 3 Variation isotherm of the dielectric loss $\tan \delta$ as function of excitation frequency

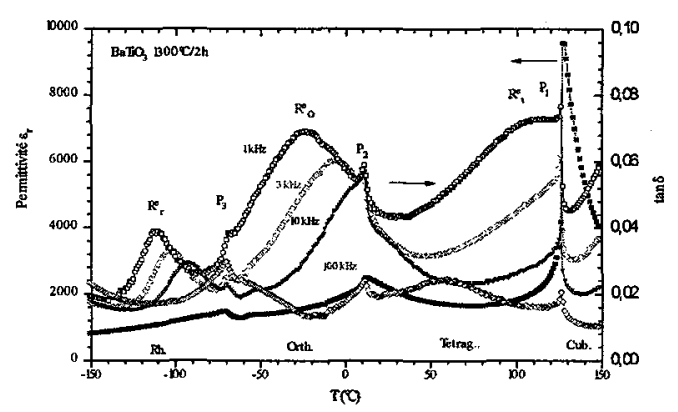

Fig. 2 Variation de dielectric loss $\tan \delta(\mathrm{T})$ and permittivity $\varepsilon_{\mathrm{r}}(\mathrm{T})$ in $\mathrm{BaTiO}_{3}$ ceramic with large grain sizes

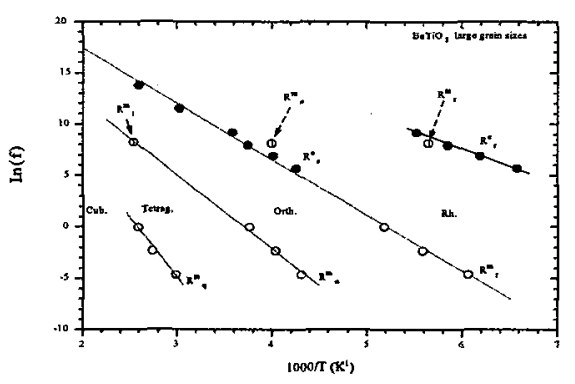

Fig. 4 Arrhenits plot of the relaxation processes in $\mathrm{BaTiO}_{3}$ ceramic with large grain sizes

In order to verify whether those loss peaks are due to a pyroelectrical effect, the dielectric losses are measured at constant temperature as a function of excitation frequency. Fig. 3 shows clearly that the peak frequency is shifted to higher value as increasing the measuring temperatures in the tetragonal phase.

According to the Arrhenius equation, the relaxation rate can be written as [9] : $\tau=\tau_{0} \exp (\mathrm{H} / \mathrm{kT})$, where $T$ is the absolute temperature and $\mathrm{k}$ is the Boltzmann's constant, $\mathrm{H}$ is the activation energy, $\tau_{0}$ is the inverse of frequency factor. For a Debye peak, the condition for the peak is $\omega \tau=1$. This gives:

$$
\ln \mathrm{f}=-\ln \left(2 \pi \tau_{0}\right)-\mathrm{H} / \mathrm{k} \mathrm{T}_{\mathrm{P}} \text {, }
$$

where $T_{P}$ is the peak temperature, $\omega=2 \pi f, f$ is the vibration frequency. From the above results on the peak temperature and the vibration frequency, the activation energy $\mathrm{H}$ and $\tau_{0}$ of peaks $\mathrm{R}$ 's are determined 
for all the peaks as Table 1. The height of R-peak in the R-phase decreases as increasing of vibration frequencies. However, the $\mathrm{R}_{\mathrm{o}}^{\mathrm{e}}$ peak in the $\mathrm{O}$-phase at $1 \mathrm{kHz}$ can pass the Orth.- Tetrag. phase transition, and exist in the T-phase for $100 \mathrm{kHz}$. The relationship between peak temperatures and vibration frequencies is plotted in the Fig. 4.

Table 1 Parameters of the relaxation peaks in the $\mathrm{BaTiO}_{3}$ ceramic with large grains sizes

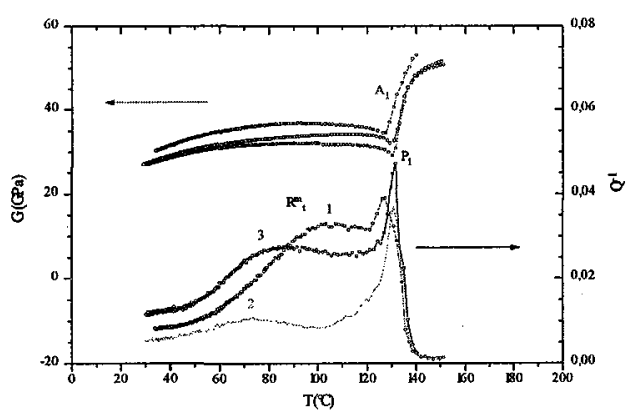

Fig.5 Influence of thermal treatment on the mechanical loss and the shear modulus in the tetragonal phase

\begin{tabular}{|l|c|c|c|c|}
\hline & $\mathrm{R}_{\mathrm{r}}^{\mathrm{e}}+\mathrm{R}^{\mathrm{m}}{ }_{\mathrm{r}}$ & $\mathrm{R}_{\mathrm{r}, \mathrm{0}}^{\mathrm{m}}+\mathrm{R}^{\mathrm{e}}{ }_{0, \mathrm{t}}$ & $\mathrm{R}^{\mathrm{mi}}{ }_{0}+\mathrm{R}^{\mathrm{m}}{ }^{\mathrm{m}}$ & $\mathrm{R}^{\mathrm{min}}{ }_{\mathrm{t}}$ \\
\hline$\tau_{0}(\mathrm{~s})$ & $2 \times 10^{-15}$ & $9 \times 10^{-14}$ & $4 \times 10^{-14}$ & $3 \times 10^{-15}$ \\
$\mathrm{H}(\mathrm{eV})$ & 0.29 & 0.47 & 0.68 & 0.92 \\
\hline
\end{tabular}

Fig. 5 shows the results of $Q^{-1}(T)$ and $G(T)$ in the tetragonal phase for the frequency of $0.1 \mathrm{~Hz}$. The curve 1 corresponds to the results without thermal treatment: one high peak $R_{t}^{\mathrm{m}}$ is located at $104^{\circ} \mathrm{C}$; the curve 2 gives the results after annealing at $950^{\circ} \mathrm{C}$ for $6 \mathrm{~h}$ in vaccum $(2 \mathrm{~Pa})$ : the peak height is drastically reduced and the temperature of the peak $\mathrm{T}_{\mathrm{P}}$ shifts to $68^{\circ} \mathrm{C}$. After annealing at $650^{\circ} \mathrm{C}$ for $2 \mathrm{~h}$ in air in-situ, the peak height is partially recovered and the $T_{P}$ shifts to $82^{\circ} \mathrm{C}$, as shown by curve 3 . Those means that the relaxation process is influenced by the oxygen vacancies induced during high temperature annealing in vaccum.

\section{DISCUSSION}

\subsection{Activation parameters of the relaxation peaks}

The values of relaxation time $\tau_{0}$ of all the relaxation processes are similar to the Debye frequency $v^{-1} \mathrm{D}$ (about $10^{-13} \mathrm{~s}$.), so the relaxation peaks could be attributed to point defect diffusion. What kinds of point defects? Lewis et al. [10] have calculated activation energies for diffusion of $\mathrm{V}_{\mathrm{Ti}}$ ", $(15 \mathrm{eV}), \mathrm{V}_{\mathrm{Ba}}$ " $(3.4$ $\mathrm{eV}$ ), and $\mathrm{V}_{\mathrm{O}} "(0.62 \mathrm{eV})$. They have also given the experimental results of $\mathrm{V}_{\mathrm{Ba}} "(2.8 \mathrm{eV})$, and $\mathrm{V}_{\mathrm{O}}{ }^{\circ}(0.44$ $0.68 \mathrm{eV}$ ). The activation energy of oxygen vacancy of $0.59 \mathrm{eV}$ was found in undoped $\mathrm{BaTiO}_{3}$ by Shirasaki et al.[11]. All those results show that the most mobile point defect in the $\mathrm{BaTiO}_{3}$ is oxygen vacancy. From where comes the oxygen vacancy in the $\mathrm{BaTiO}_{3}$ ceramic? There always exist certain impurities substitutions at position of $\mathrm{Ti}^{+4}$, such as $\mathrm{Fe}^{3+}{ }^{2+}, \mathrm{Sr}^{2+}, \mathrm{Ca}^{2+}, \mathrm{K}^{+}, \mathrm{Na}^{+}$. Such impurities with negative charges in $\mathrm{BaTiO}_{3}$ are compensated by the oxygen vacancy. In this way the oxygen vacancies exist always in the material. The relaxation peaks could be due to the interaction between domain walls and oxygen vacancies.

\subsection{The memory effect of domain walls structures}

One relaxation peak can pass from one crystalline phase to other with increasing frequency. Those results implies that the $\mathrm{BaTiO}_{3}$ ceramic can keep some parts of domain wall structures in the ferroelectric phase, even if the crystalline structure is changed from rhombodral to orthorhombic, even to the tetragonal phase. This kind of behavior in the $\mathrm{BaTiO}_{3}$ is called a «memory effect» of the domain structures. Such proposition has found direct evidence in microscopic observation by Oh et al. [12]. Similar domain walls structure exists in the different ferroelectric phases.

\subsection{Possible mechanism of relaxation process in Barium Titanate Ceramics}

Arlt and Sasko [13] pointed out that configuration of domain walls structure depends on the grain size. In the ceramic with large grains there exists always certain configurations which can respond to mechanical and electrical excitation in the ferroelectric phase. So the relaxation peaks could be observed in the 
tetragonal, orthorhombic, and rhombohedral phase. Concerning the mechanism of the relaxation peak, Postnikov et al. [7] have proposed that interaction of mobile point defects with immobile domain walls by piezoeffect can induce a relaxation peak. For small concentrations of mobile charges, as in undoped ceramic, the height of mechanical loss peak is

$$
Q^{-1}{ }_{\max }=2\left(d_{33}-d_{31}\right)^{2} c_{0} L^{2} / \pi^{4}\left(\varepsilon_{0} \varepsilon_{r}\right)^{2} k T s
$$

where $c_{0}$ is the density of mobile point defects, $L$ is width of domain, $s$ is the elastic compliance, $\varepsilon_{0}$ is the permittivity in vacuum. The activation energy is the diffusion energy of point defect and the relaxation time can be written as $\tau=\mathrm{L}^{2} / \pi^{2} \mathrm{D}$, where $\mathrm{D}$ is the diffusion coefficient. For the relaxation peaks observed in $\mathrm{BaTiO}_{3}$ ceramic, the peaks are connected to the oxygen vacancies diffusion. So the relaxation peak can be observed in coarse grained ceramic because the microscopic observation shows that the width of domain is about $1 \mu \mathrm{m}$ in coarse grained ceramic, which is about 5 times than that (about $0.2 \mu \mathrm{m}$ ) in the fine grained ceramic [2].

Concerning the thermal treatments, the oxygen vacancies induced by high temperature annealing in vaccum could be located preferably at domain walls because the range of domain walls have distortion of unit cells with low energy barrier for the oxygen vacancies. Those oxygen vacancies have certain pinning effect on the domain walls, so the peak height reduces after high temperature annealing in vacuum; and can recover by further high temperature annealing in air. However, the oxygen vacancies induced by the acceptor impurities are usually located in the crystal unit cells and near the substitution atoms in order to keep electrical neutrality of the material. The relaxation peaks are mainly due to the diffusion of oxygen vacancies induced by the acceptor impurities in an electrical field induced by the variation of polarisation of the material under mechanical and/or electrical excitation.

\section{CONCLUSION}

In undoped coarse grained $\mathrm{BaTiO}_{3}$ ceramics there are four relaxation processes in the ferroelectric phases. And one relaxation process can exist in all the ferroelectric phases, which means that the material keeps certain memory of the domain walls structures. The activation energy of each relaxation process is determined as $0.3,0.5,0.7$ and $0.9 \mathrm{eV}$, respectively. Those relaxation processes can be explained by an interaction of domain walls and diffusion of oxygen vacancy in the domains. Those oxygen vacancies are induced by the impurities in keeping the electrical neutrality of the material. However, the oxygen induced by high temperature annealing can limit the movement of domain walls.

\section{References}

[1] Sheppard L.M., Silicates Industriels, (1993) 118.

[2] Cheng B.L., Gabbay M., Fantozzi G., and Duffy W. Jr., J. Alloys and Compounds 211/212(1994) 352.

[3] Duffy W Jr., Cheng B.L., Gabbay M., and Fantozzi G., Metall. Trans. 26A (1995) 1735.

[4] Ikeda T., J. Phys. Soc. Japan, 12 (1958) 809.

[5] Zhang J.X., Zhen W., Fung P.C.W., and Liang K.F., J. Alloys and Compounds (1994) 211/212(1994) 378.

[6] Fousek J., and Brezina B., J. of Phys. Soc. Japan, 19 (1964) 830.

[7] Postnikov P.V., Pavlov V.S., Gridnev S.A., and Turkov S.K., Soviet Phys.-Solid State, 10 (1968)1267.

[8] Arlt G. and Dederiches H., Ferroelectrics, 29 (1980) 47.

[9] Nowick A.S., and Berry B.S., "Anelastic Relaxation in Crystalline Solids", (Academic Press, New York, Chap. 3 ,1972).

[10] Lewis G.V., Catlow C.R.A., and Casselton R.E.W., J. Am. Ceram. Soc., 68 (1985) 555.

[11] Shirasaki S., Yamamaura H., Haneda H., Kakegawa K., and Moori J., J. Chem. Phys. 73 (1980)4640.

[12] Oh K.Y,Uchino K., and Cross L.E., J. Am. Ceram. Soc., 77 (1994) 2809.

[13] Arlt G., and Sasko P., J. Appl. Phys., 51, (1980) 4956. 